\title{
Ethos y pluralidad: consideraciones sobre la percepción de las matices del locutor en la materialidad enunciativa de la lengua extranjera.
}

\section{Ethos and plurality: considerations about the perception of the nuances of the speaker in the enunciative materiality of the foreign language.}

Ivani Cristina Silva FERNANDES ${ }^{1}$

(Universidade Federal de Santa Maria UFSM)

\begin{abstract}
Resumen: El objetivo de este trabajo es discutir sobre el papel de la imagen discursiva, es decir, el ethos, como elemento orientador de las reflexiones sobre la pluralidad lingüística y/o cultural en las clases de lengua extranjera, en particular del español para brasileños.

La idea de pluralidad implica un cuestionamiento sobre como consideramos las nociones de identidad y alteridad, ya que es en la materialidad lingüística que el sujeto se (re)construye a cada momento que enuncia, según los conceptos benvenistianos. Como nos recuerdan las "Orientações curriculares para o ensino médio 2", la enseñanza de una lengua extranjera debe promover un debate sobre el sentimiento de inclusión y los valores "globalizantes" en lo que se refiere al conocimiento de una nueva lengua. Por lo tanto, una de las formas de presentar tal debate es pensando cómo la imagen de los interlocutores y sus efectos se (re)elaboran en la materialidad de una lengua extranjera.
\end{abstract}

Palabras-clave: Ethos. Pluralidad. Enunciación. Cultura.

\begin{abstract}
This paper aims at discussing the role of the discursive image, that is, the ethos, in the reflection about the linguistic and/or cultural plurality in foreign language classes, notably in the teaching of Spanish to Brazilians. The idea of plurality entails the questioning about how the notions of identity and alterity are considered, since the enunciative subject (re)constructs himself in linguistic materiality every time he enunciates, as propounded by Benvenistian concepts. According to the "Orientações curriculares para o ensino médio", the teaching of a foreign language should promote the discussion about the sense of inclusion and "globalizing" values in what regards the acquisition of a new language. Therefore, a way to present such debate is to think of how the image of the interlocutors and its effects can be (re)elaborated in the materiality of a foreign language.
\end{abstract}

Keywords: Ethos. Plurality. Enunciation. Culture.

\section{INTRODUCCIÓN}

El término "pluralidad", del latín pluralítas, tiene en su origen el sentido de "múltiple, calidad de ser más de uno', lo que nos remite a la cuestión de reconocer a sí mismo y al Otro no solo como una cuestión de cantidad, sino también como una discusión sobre la diversidad de varios elementos distintos en un espacio determinado. De este modo, repasamos a los orígenes del término para recordar el principal debate que se establece cuando pensamos sobre la pluralidad: las diferencias (con)viviendo en determinados espacios, lo que forma una unidad que, a su vez, conlleva una sensación de pertenencia entre los individuos. Esta pluralidad no es pasible de ser aprehendida o controlada en su totalidad, pero podemos

\footnotetext{
${ }^{1}$ Professora adjunta de Licenciatura em Letras / Espanhol e do Curso de Pós-Graduação em Letras (Estudos Linguísticos) da Universidade Federal de Santa Maria (UFSM/RS). E-mail: icrisifer@gmail.com

2 Documento oficial del Ministerio de la Educación de Brasil, cuyo objetivo es guiar los profesionales de las escuelas públicas en su trabajo en diversas áreas del conocimiento. El documento citado se refiere al campo de "Linguagem, códigos e suas tecnologias".
}

(C) Revista Moara, n.42, jul.-dez. 2014, Estudos Linguísticos. ISSN 2358-0658 (Impresso).

Programa de Pós-Graduação em Letras / Universidade Federal do Pará. Todos os direitos reservados. 
cuestionarla e identificar las posibles relaciones entre esta y la construcción de la identidad y la alteridad.

Al comentar sobre la identidad cultural en la postmodernidad, Hall (2006, p.13) defiende que el sujeto postmoderno no tiene una identidad fija, esencial o permanente y, por ello, tal elemento se transforma continuamente en los ámbitos en que somos interpretados o interpelados en nuestros sistemas culturales, lo que significa que la cuestión de la identidad es una definición histórica. Como consecuencia, la noción del sujeto implica que trabajemos con lo inestable, con lo plural y con lo fragmentario. Es la muerte del sujeto cartesiano, enunciado demasiadamente repetido en los ámbitos filosóficos cuando se discute sobre este tema.

Por otro lado, según Schöpke (2010, p. 20), la alteridad representa el "otro", algo que se presenta como oposición y descentra el "yo". Sin embargo, no la vemos como algo necesariamente "antagónico" a la identidad, sino como entidad que nos integra en la experiencia de la intersubjetividad. Como nos resalta Silva (2012, p. 28):

\begin{abstract}
O sujeito nunca se constituirá totalmente como realidade fechada em si mesma, porque a subjetividade não é mais do que a ação de tornar-se sujeito, constantemente reiterada. E a alteridade faz parte desse processo, porque a ação de tornar-se sujeito inclui a constante alteração de si e nunca a repetição do mesmo. Nesse sentido, o tempo e a história não são acidentais: subjetividade, temporalidade e historicidade não se separam e não há nenhum predicado capaz de definir o sujeito definitivamente, porque o seu ser consiste num contínuo fazer-se.
\end{abstract}

Por lo tanto, al pensar sobre estas nociones, pluralidad e identidad / alteridad, notamos que están implicadas, pues la identidad es algo relacional y tiene el rasgo de la diferencia como nos explica Woodward (2007, p. 09) al comentar el caso de las identidades nacionales en que una identidad A se define con relación a una identidad B. La identidad A no es la $\mathrm{B}$, pero la primera necesita la segunda porque esta proporciona a aquella condiciones para que su identidad exista.

Como construcción individual, social y simbólica, la experiencia de construcción de la identidad y de la alteridad cohesiona estas tres instancias gracias a su capacidad de presentarse metafóricamente como una tela cuyos hilos están unidos por el lenguaje. De ahí que los estudios de las lenguas maternas y extranjeras, a menudo, se involucran con la problemática de la formación del individuo, del ciudadano y del sujeto discursivo. Como nos recuerda Revuz (1997, p. 217):

\footnotetext{
Muito antes de ser objeto de conhecimento, a língua é material fundador de nosso psiquismo e de nossa vida relacional. Se não se escamoteia essa dimensão, é claro que não se pode conceber a língua como simples "instrumento de comunicação". É justamente porque a língua não é em princípio, só um "instrumento", que o encontro com outra língua é tão problemático, e que ela suscita reações tão vivas, diversificadas e enigmáticas. Essas reações se esclarecem um pouco se for levado em consideração que o aprendiz, em seu primeiro curso de língua, já traz consigo uma longa história com a sua língua.
}

De esa manera, el trabajo con la lengua extranjera no solo permite iniciar un proceso de construcción de un "yo" en lengua extranjera, sino también permite reflexionar sobre nuestro propio proceso de (re)elaborarnos en nuestra propia lengua a partir de la reflexión sobre la experiencia y la perspectiva del otro. Como consecuencia, en las Orientaciones Curriculares de la Enseñanza Media, se enfatiza, en varios fragmentos, el papel de las lenguas extranjeras en la formación integral de los individuos. Al considerar que los cuatro ejes estructurales de la educación, según UNESCO, se basan en aprender a 'conocer', a 'hacer', a 'vivir' y a 'ser', la enseñanza de lenguas extranjeras no se limita a una cuestión instrumental de 
comunicación, pues se ubica en el campo de construcciones de valores, sentidos, saberes y representaciones.

Incluso, es importante destacar el valor del verbo 'representar', que se puede concebir como una síntesis de tales ejes, una vez que, para construir una representación de sí mismo y del Otro, es necesario:

a) saber (re)conocerse a sí y al otro en su fraccionamiento y en su multiplicidad en las representaciones;

b) saber (re)hacer las varias representaciones por la cuales nos constituimos;

c) saber (re)vivir cada representación como parte de nuestra identidad;

d) saber ser las diversas representaciones al promover la integración entre estas.

Este recorrido hasta tal punto tiene como objetivo el de enfatizar el protagonismo del sujeto y su relación con la(s) lengua(s) / el lenguaje. Estamos de acuerdo con Maite Celada (2007) cuando, al tratar de la enseñaza del español para brasileños, llama la atención sobre la capacidad de la lengua extranjera de propiciar otros saberes discursivos y de atravesar el campo de la subjetividad. Por lo tanto, se debería pensar en la relación entre sujeto y lengua(je) y no necesariamente en la difusión de una determinada lengua extranjera en si.

Por ello, nos proponemos a discutir sobre la cuestión de la pluralidad lingüística y/o cultural por medio de la cuestión de la imagen del locutor en la materialidad lingüística, más específicamente, sobre el conocimiento y el trabajo con el ethos en la materialidad de la lengua a partir de una perspectiva de la Enunciación. Tal discusión se dará dentro del contexto de la enseñanza y del aprendizaje del español como lengua extranjera en las clases de la red pública, debido al reconocimiento de la importancia de las lenguas extranjeras en el escenario de la educación básica brasileña en lo que se refiere a la formación del ciudadano reflexivo y actuante en la sociedad, ya que se pretende "levar o estudante a ver-se e constituir-se como sujeito a partir do contato e da exposição ao outro, à diferença, ao reconhecimento da diversidade" (BRASIL, 2006, p. 133).

\section{Fundamentación teórica: un recorrido hacia la noción de ethos, de Lingüística de la Enunciación y de Cultura}

Para seguir con nuestra discusión, es necesario que aclaremos algunos conceptos que son claves para entender los comentarios que pretendemos realizar sobre la cuestión de pluralidad. Para iniciar nuestro recorrido por las nociones teóricas, con base en Flores y Teixeira (2005), concebimos la Lingüística de la Enunciación como un área que abarca varias teorías que contribuyen, con diferentes perspectivas, a una reflexión sobre los procesos enunciativos a partir de la relación con las ideas de Saussure. Y, de este modo, la enunciación se convierte en el eje para pensar los procesos de cómo el hombre se marca en la lengua

$\mathrm{Al}$ seguir los principios benvenistianos, también entendemos la idea de que la enunciación es un estado de funcionamiento de la lengua debido a un acto individual de uso (BENVENISTE, $2006^{3}$, p. 82). La enunciación es irrepetible y deja como materialidad de su manifestación el enunciado (FLORES et alii, 2009). Será en el enunciado que el sujeto dejará sus marcas al revelarse, como nos recuerda Fiorin (2005, p. 31). De este modo, el enunciado surge no como una materialidad estructural y abstracta de la gramática, sino como un elemento del discurso en que se entablan las interrelaciones entre forma y sentido. Es a partir de los enunciados, de su materialidad en las modalidades oral y escrita, que podemos

\footnotetext{
3 Aunque el trabajo "O aparelho formal de enunciação" se localiza en el libro Problemas de Lingüistica Geral II, $1^{\text {a }}$ edición brasileña de 1989, Benveniste publicó tal artículo en 1970.
} 
identificar y relacionar los sentidos y su emergencia a medida que los sujetos se apropian de la lengua al asumir su papel de coenunciadores en la interpretación.

Nos parece primordial destacar la relación entre forma y sentido, vinculada a una práctica de lenguaje, pues, según Mari (2008, p. 11), no debemos pensar la cuestión de los sentidos solo como la emergencia del funcionamiento de la lengua, sino también como la emergencia de las prácticas del lenguaje. Y tales prácticas son plurales y dejan sus rasgos en la lengua y en las vivencias culturales. En realidad, cuando nos referimos a la noción de pluralidad, nos damos cuenta de que discutirla implica cuestionar las propias características, inclusiones, límites de la percepción de "sujeto", "cultura" y "lengua".

Conviene también señalar que los conceptos de "enunciación” y "enunciado" nos parecen imprescindibles en la discusión de la pluralidad en lengua extranjera, en particular en el español, porque los sentidos de la pluralidad se pueden observar en el discurso y en sus unidades y no en elementos aislados de la gramática normativa, como la oración. Por otro lado, estos mismos conceptos nos permiten también trabajar con la noción del sujeto enunciante que se aleja del sujeto psicobiológico de la Pragmática.

A partir de las ideas greimasianas y ducrotianas, entendemos el enunciador como imagen del locutor construida en y por la materialidad lingüística. Por ello, el enunciador es una entidad presupuesta en la existencia del enunciado y que articula las diversas voces que habitan en tal unidad. Como paralelo, también presentamos la figura del enunciatario que, igual al enunciador, es una imagen construida en el discurso y está presupuesta en el enunciador. Juntos, enunciador y enunciatario permiten que haya una (re)construcción aproximativa y conjunta de la enunciación a partir del enunciado, caracterizando el proceso de coenunciación, del cual también surgen los efectos de sentido de la pluralidad lingüística y/o cultural.

$\mathrm{Al}$ dirigir nuestra mirada hacia las figuras de los enunciadores, notamos que existe una cierta "manera de decir", que Maingueneau (2008, p. 99) identifica como una construcción del ethos, y tal manera nos orienta en el momento de concebir los sentidos. Amossy (2006, p. 220), por su vez, conceptúa el ethos como una imagen que el locutor construye en el discurso sobre sí mismo con el objetivo de influir sobre su interlocutor, concepto que proviene de los estudios de la Retórica y del Análisis del Discurso. Es pertinente enfatizar que estas (re)construcciones, verdaderos esbozos de imágenes discursivas, se elaboran a partir de otras imágenes y representaciones y de tendencias enunciativas que son recurrencias de una o algunas estructuras lingüísticas que caracterizan una forma de decir en una modalidad oral o escrita.

De ese modo, la emergencia del sujeto en la lengua, muchas veces, se materializa en el esbozo de un ethos del enunciador y en los efectos patémicos en la figura del enunciatario, es decir, un simulacro de emoción, que auxilia en la caracterización del interlocutor. Tal simulacro es concebido como efecto calculado y no necesariamente alcanzado. De esa forma, las imágenes discursivas se transformarán en eje de discusión para que podamos pensar sobre la pluralidad lingüística y cultural.

Asimismo, el ethos tiene una dimensión verbal y una dimensión, digamos, "visual". Algunos investigadores la conceptúan como "fiador", una construcción que se da a partir de la percepción del interlocutor. Maingueneau (2008, p. 18) lo vincula al ethos al discutir como la representación ética ${ }^{4}$ necesita una voz relacionada con un cuerpo enunciante que está especificado históricamente.

Esse ethos recobre não só una dimensão verbal, mas também o conjunto de determinações físicas e psíquicas ligados ao "fiador" pelas representações coletivas

\footnotetext{
${ }^{4}$ Adjetivo relativo al ethos.
} 
estereotipadas. Assim, atribui-se a ele "caráter" e uma "corporalidade", cujos graus de precisão variam de acordo com os textos. O "caráter" corresponde a um feixe de traços psicológicos. Quanto à "corporalidade", ela está associada a uma compleição física e a uma maneira de vestir-se. Mais além, o ethos implica uma maneira de se mover no espaço social, uma disciplina tácita do corpo apreendida através de um comportamento. O destinatário a identifica apoiando-se num conjunto difuso de representações sociais avaliadas positiva ou negativamente, em estereótipos que a enunciação contribui para confrontar e transformar [...]. De fato, o fiador implica ele mesmo em um "mundo ético" do qual ele é parte pregnante e ao qual ele dá acesso. Esse "mundo ético" ativado pela leitura subsume um certo número de situações estereotípicas associadas a comportamentos [...].

Para finalizar este apartado, es esencial discutir algunas perspectivas vinculadas a la noción del término 'cultura' en el contexto de enseñanza de lenguas. Son muchas las referencias en este tema, pero nos basamos en los trabajos de Nardi $(2007,2010)$ sobre la relación entre sujeto, cultura e identidad en el libro didáctico en E.L.E. a partir de una mirada discursiva.

En su tesis defendida en 2007, la investigadora observa que, comúnmente, se concibe la cultura como un conjunto de reglas que se puede aprehender en su totalidad, por el cual se construye un imaginario sobre el otro. Así, con base en las ideas de Bosi (2000), Nardi resalta que se piensa la cultura como un artefacto cultural, es decir, como una manifestación cultural específica, por la cual se manifiestan los sentidos que están presentes en el funcionamiento de una comunidad. Tal pensamiento implica que el sujeto discente asuma el papel de espectador pasivo que retiene la información sin cuestionar las relaciones existentes y sus contextos. Por otro lado, la cultura se limita a ser un aspecto motivacional o es empleada como subterfugio para iniciar un trabajo con estructuras gramaticales.

Ahora bien, la autora defiende la idea de que la cultura es un espacio de criticidad e interpretación en que los sujetos deben cuestionar su vínculo con los demás y con la naturaleza a partir de determinados lugares. De ese modo, Nardi (2010, p. 397) señala que:

a cultura deve ser vista, portanto, como um lugar de interpretação. Assim compreendida, seu estudo se torna, no ensino-aprendizagem de segunda língua, um momento propício de promoção de deslocamentos capazes de possibilitar que o aprendiz venha a pensar nos processos discursivos produzidos na língua do outro e no modo como nesses discursos os sentidos são produzidos. Passa-se, assim, do simples registro de um imaginário sobre o outro para o questionamento de sua cristalização, o que implica afastar-se da compreensão da pluralidade cultural como um espetáculo de variedade [...].

Al considerar la cultura de tal modo, su noción entabla relaciones sinonímicas con la pluralidad, una vez que se convierte en el espacio de perspectivas y modos de comprensión traspasadas por sus respectivos discursos. La pluralidad, entendida de esa manera, no abarca la idea tradicional de estereotipo, unidad fija y con perspectiva ilusoria de comprensión y delimitación.

\footnotetext{
A idéia de que a cultura cristaliza-se talvez tenha sido a responsável por fazer com que com tanta força se tenham produzido (e se produzam, e repitam) os estereótipos: essa espécie de caricatura que antes engessa uma cultura do que nos permite pensá-la como um sistema poroso e dinâmico. Produz-se, pelo estereótipo, um fechamento, que longe de promover o reconhecimento da cultura, torna opaca nossa compreensão. Há um distanciamento em relação ao outro que dificulta a identificação com esse lugar, duro e fechado, que repele o sujeito ao pressupor não a criação de uma identidade, mas a silenciosa aceitação dos limites desse espaço.
} 
Num movimento contrário, o estereótipo pode criar para o sujeito a ilusão de dominar o outro e sua verdade, porque ao simplificá-lo, ao reduzi-lo a umas poucas marcas constantes e facilmente identificáveis, forja-se a ilusão de que lhe é permitido conhecê-lo por inteiro e, portanto, dominá-lo, dizê-lo. Em termos de ensino-aprendizagem de uma segunda língua essa parece ter sido a voz dominante sobre a cultura: a do outro como um conjunto de traços reconhecíveis que permitem ao sujeito dominá-lo e, se o desejar, ocupar o seu lugar. Esse modo de representação do lugar do outro cria espaços de discriminação pelo apagamento de seus efeitos, já que está baseado em regimes de verdades (NARDI, 2007, p. 68).

En este punto, nos parece evidente que la lengua conlleva rasgos de la cultura indisociables del sujeto. Sin embargo, tales rasgos no siempre se pueden reconocer fácilmente, tampoco son transparentes. De ahí que sea necesario un trabajo de cuestionamiento del lugar del 'yo 'y del 'otro 'en este escenario en que se mueven lo histórico, lo social y lo ideológico. Por otro lado, también se pone de manifiesto la importancia en pensar sobre los espacios enunciativos y contextos de producción de estos discursos sobre la(s) cultura(s).

En suma, referirse a la cultura es explicitar la pluralidad en lo tocante al discurso y a la lengua, lo que implica concebirla como el movimiento de ponerse en el lugar del otro para, posteriormente, volver a ponerse en su lugar de forma más consciente y reflexiva, desencadenando una perspectiva de flexibilidad y empatía con relación a lo diferente que se ubica fuera y dentro de uno mismo. La pluralidad es un lugar de construcción e intercambio de vivencias y, por ello, también es un lugar de movimiento y reflexión. En nuestra opinión, esta es la clave para pensar la cuestión de pluralidad en la enseñanza de una lengua extranjera que no se limite al fin inmediato y utilitario de lo que se resume frecuentemente "aprender una lengua para comunicarse".

\section{El ethos y la pluralidad: una propuesta de trabajo.}

Tras las consideraciones realizadas, es basilar proponer un modo más concreto de reflexión y cuestionamiento sobre las perspectivas aquí defendidas. Para esta finalidad, elegimos dos muestras del género "viñeta" que tratan sobre temas actuales, de forma crítica, pero que recurren, implícitamente, a aspectos culturales y estereotipados. Como pretendemos identificar elementos de la materialidad lingüística que nos lleven a cuestionar el proceso de cómo se esboza el ethos del enunciador, decidimos elegir textos que abarcasen una perspectiva de la realidad del otro, a saber, la representación de una perspectiva de un locutor español hacia un suceso brasileño y, al revés, un locutor brasileño que articula una perspectiva sobre una problemática de la sociedad española. Lo ideal es que este intercambio de puntos de vista no se limitara a dos países, sino que hubiera una red discursiva compuesta de varios textos sobre una circunstancia social del otro. Sin embargo, al tener en cuenta los objetivos de este trabajo, concentramos nuestro enfoque en dos muestras, a título de ejemplo.

Metodológicamente, para guiar nuestro análisis, nos basamos en el paradigma indiciario, que, de acuerdo con Ginzburg (1989, p. 152), es un modelo de esencia morelliana que revela "um saber de tipo veneratório", determinado por la "capacidade de, a partir de dados aparentemente negligenciáveis, remontar a uma realidade complexa não experimentável diariamente". En otras palabras, tal paradigma valora los sutiles rasgos o indicios para construir un análisis sobre un conjunto complejo. En nuestro caso, buscaremos los más implícitos elementos de la materialidad lingüística para esbozar el perfil de un ethos que nos auxilie en la discusión sobre la pluralidad.

En este caso, buscamos identificar, en la materialidad, cómo se da la producción de sentido, comprendida aquí, de acuerdo con Mari (2008, p. 100), como un conjunto formado por procedimientos (condiciones que la lengua nos ofrece para la construcción de sentidos) y 
por efectos (las consecuencias que se derivan de la percepción de determinados hechos). Pese a todo ello, conviene recordar que los sentidos no están en el texto, sino que se dan a partir de la perspectiva de los interlocutores sobre tales procedimientos y efectos en esta materialidad, lo que posibilita la identificación de discursividades en un proceso de coenunciación, ubicado en determinado momento histórico. En síntesis, de acuerdo con este punto de vista, el sentido se da en la interrelación entre materialidad lingüística, sujeto y contexto de producción.

Con base en el trabajo de Romualdo (2000), definimos la viñeta como un texto de carácter lingüístico e imagético, que promueve una crítica, de forma condensada y densa, sobre un tema de la actualidad, usando como recursos la intertextualidad, la polifonía y el humor. Como hemos afirmado anteriormente, para los objetivos de este trabajo, analizaremos dos muestras textuales, de un dibujante brasileño y de un español, que se refieren a una visión sobre el Otro $^{5}$ a partir de sucesos de la actualidad en aquel momento. Es importante destacar que, para ello, los autores emplean recursos que suscitan una discusión sobre estereotipos y pluralidad.

La primera viñeta, de Erlich, se publicó en el periódico El País, en 18/06/2013, en ocasión de las protestas en Brasil:

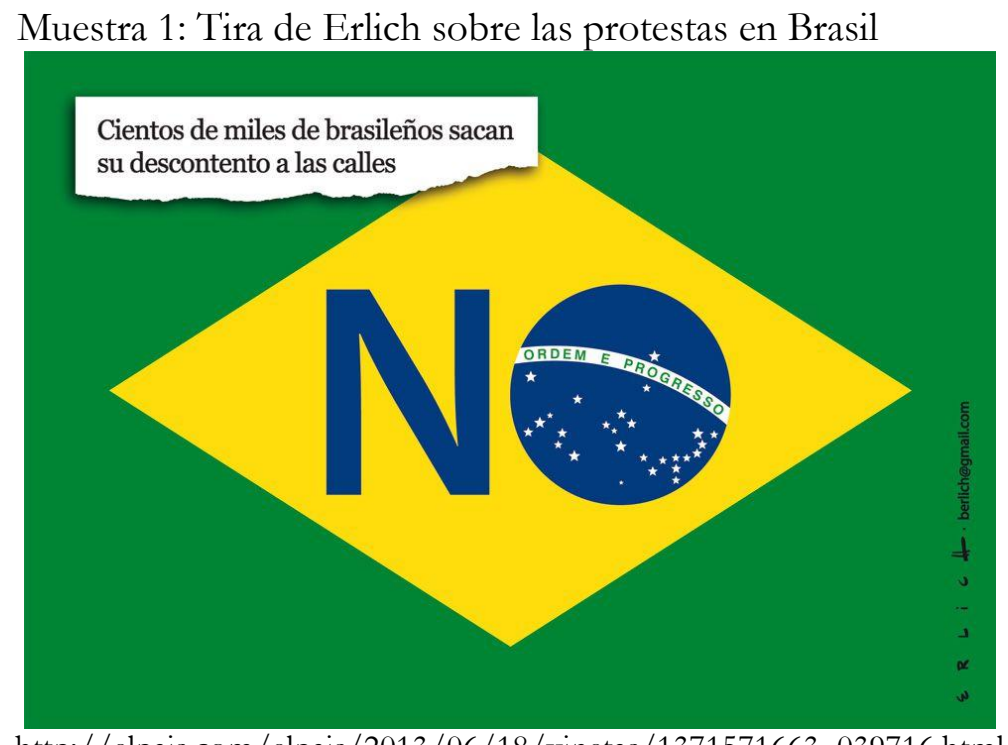

En esta muestra, se construye una perspectiva específica sobre un acontecimiento de gran repercusión mundial justamente por contradecir un estereotipo sobre el carácter brasileño: el de sujeto con rasgos cordiales, pacíficos y evasivos.

Como forma de condensar más ágilmente la esencia del tema, ubicando el lector en cuanto al contexto de producción, se alude al hecho histórico y al contexto social por medio de la intertextualidad del titular, conjugado con la referencia a la bandera nacional, uno de los símbolos máximos del sentimiento de pertenencia y cohesión identitaria nacional. En tal caso, nos llama la atención, en primer lugar, la intertextualidad entre un posible titular que enfatiza el "descontento brasileño" y la "materialidad imagética" (la figura de la bandera brasileña).

En el titular típico, en términos estructurales, tenemos una oración simple en orden directo (Sujeto+Verbo+Objeto Directo+Complemento Circunstancial) en que se destaca el

\footnotetext{
${ }^{5}$ Como se observa en la literatura especializada en el área de la Filosofía, utilizamos la grafía de Otro con letra mayúscula para referimos a una entidad y no a un sujeto psicobiológico.
} 
verbo "sacar" en el sentido de "mostrar o expresar" que enfatiza la manifestación del "descontento" (OD) brasileño. Además, en la posición de sujeto (posición relevante sintácticamente) tenemos el sintagma "cientos de miles" que expresa el número significativo de manifestantes.

La estructura oracional solo nos interesa en su dimensión enunciativa, ya que el sintagma "ciento de miles" asume efectos de sentido al direccionar a una cantidad incierta e impactante. Por otro lado, el verbo "sacar" juega con algunas de sus acepciones de "poner algo o alguien fuera del lugar; manifestar algo" y sus efectos de sentido de vislumbre de algo que estaban implícitos.

Sin embargo, este efecto de sentido del titular adquiere otra dimensión al "dialogar" con la figura simbólica de la bandera brasileña "modificada". Al lado del círculo, en que se ubica el enunciado "ordem e progresso", notamos la presencia de la letra "N", lo que construye el enunciado formado por el adverbio "NO".

Tal enunciado puede producir dos efectos de sentido, por lo menos. La primera hipótesis es leer el enunciado "NO" como correspondiente del término español "ibasta (ya)!", una palabra que expresa indignación y/o reivindicación, casi un "slogan" muy presente en pancartas, manifiestos y otros materiales que están en contextos de protestas (como vemos en los movimientos sociales como 'Los Indignados`en España, por ejemplo). La segunda hipótesis es que este enunciado esté formado por un sintagma - No "ordem e progresso" que enfatiza, implícitamente, los motivos y/o e la percepción de los manifestantes. La supuesta ausencia de orden y progreso puede ser uno de los motivos de descontento.

Independientemente del caso, el adverbio "no", construido por la letra "N" y la letra "O", letra que también forma parte de una de las figuras geométricas de la bandera, es relevante para entender la perspectiva crítica con relación a esta circunstancia. En este caso, discutir los efectos de sentido a partir de la materialidad lingüística del adverbio que combina la interrelación de las formas de las letras con las formas geométricas presentes en la bandera desencadena una discusión sobre cuál es el sujeto, cuáles características del ethos y de qué lugar simbólico él enuncia.

¿Sería un enunciador, caracterizado por el ethos colectivo español, que articula la voz de indignación de “basta (ya)!”? En este caso, tal punto de vista da lugar a la discusión sobre cómo el otro interpreta un suceso en una sociedad distinta a la suya, traspareciendo los efectos de sentido de la discursividad de este Otro. Hay un acercamiento de perspectiva debido a la suposición de sentimientos similares de indignación, pero que no necesariamente poseen las mismas manifestaciones y efectos de sentido enunciativos y discursivos.

¿Sería un enunciador que mimetiza una caracterización más cercana del ethos colectivo brasileño y articula la voz de este ¡No! que emana la ausencia de los valores nacionales icónicos expuestos en la bandera? Por otro lado, en tal hipótesis, la perspectiva predominante es que la VOz de este otro intenta asumir nuestro lugar discursivo como brasileño, que supuestamente expresa en su discurso y en sus matices enunciativos la ausencia y la presencia a la vez de los símbolos que nos caracterizan: la fuerza simbólica de la negación del sintagma que carga valores elevados en nuestro imaginario nacional y la presencia de la fuerza simbólica de la bandera y de los colores nacionales.

O ¿¿sería posible una conmutación de voces y de ethe, una vez que la materialidad enunciativa y discursiva nos permite que cuestionemos lugares simbólicos y no verdades absolutas? Como podemos darnos cuenta, tal discusión, a partir de la materialidad lingüística y de los intentos de esbozar un ethos, nos conduce hacia una reflexión sobre cómo el sujeto comprende su relación consigo mismo y con el Otro, vivenciando estar en el lugar enunciativo y simbólico suyo y del otro, pero con la posibilidad de vivenciar la experiencia críticamente. Ello no es solo un trabajo con la noción de cultura que defendemos en las clases de lengua 
extranjera, sino también es una forma más compleja y sutil de pensar la cuestión de la pluralidad a partir de la materialidad lingüística, enunciativa y discursiva entrelazadas.

En un trabajo en las clases de español como lengua extranjera, en particular en la enseñanza básica, el profesor, como mediador intercultural, puede proponer indagaciones para la construcción conjunta de reflexiones sobre los discursos implícitos en tal materialidad. En primer lugar, es conveniente orientar a la discusión a partir de algunas preguntas:

1) ¿Hay alguna voz que predomina en la viñeta y qué resulte más contundente? ¿Por qué?

2) ¿Esas voces pueden corresponder a cuáles construcciones de ethos y de fiadores?

3) ¿Cuáles trazos éticos surgen de los efectos de la presencia del sustantivo "descontento" y del adverbio "no" (en mayúscula y con su ambivalencia signo lingüístico y geométrico)?

4) ¿A qué discursividades o lugares simbólicos podemos vincular el sintagma "ordem e progresso"?

5) ¿Cuáles fiadores se construyen que correspondan a las voces sugeridas en la viñeta? ¿Te reconoces en la figura de algún fiador?

6) ¿Cuál ethos del enunciador del texto surge de esta materialidad?

7) ¿Crees que la perspectiva presente en la viñeta es coherente con el momento histórico a que se refiere? ¿Por qué?

8) ¿Cómo brasileño, te sientes representado por la viñeta? ¿Por qué?

10) ¿Cuáles los principales símbolos nacionales? ¿Cuáles son los principales discursos, simbologías que los sintetizan?

Independiente del metalenguaje, que debe estar restricto a este trabajo y no traspuesto tal cual en las clases de lengua española, es importante pensar en cuestiones que auxilien en una discusión sobre los ethe, voces y lugares discursivos que se entrelazan en este discurso. Posteriormente, se podría seguir con el trabajo de cuestionamiento a partir de otras propuestas como:

9) Presenta otra viñeta publicada en Brasil y en otro país hispanohablante sobre las protesta de junio de 2013 en el territorio brasileño.

10) Identifica las principales coincidencias y diferencias presentes entre esas viñetas y la de Erlich.

11) ¿Hay influencia ideológica entre viñeta y suporte / medio de circulación (prensa escrita y on line)?

12) Identifica y caracteriza los rasgos de una viñeta.

13) Investiga la correlación entre la bandera brasileña (formatos y colores), sus posibles simbologías y contexto histórico en que fueron concebidas. Haz el mismo proceso con una bandera de un país hispanohablante.

14) Elabora una viñeta sobre el mismo tema y, posteriormente, explica cuál sería la posible crítica presente, la imagen discursiva que quieres transmitir de ti como enunciador y cómo imaginas los interlocutores de tu viñeta.

15) Discute los motivos, objetivos y características de las protestas en Brasil y en otros países.

En este proceso de producción oral y escrita, los estudiantes tendrán la oportunidad de ponerse en el lugar del otro para, después, vivenciar, de forma más consciente, cómo es estar en su lugar. Asimismo, es una oportunidad de analizar los "entramados" entre los elementos linguísticos y cómo uno se hace sujeto en una lengua y cómo se hace sujeto en otra. Es decir, cómo "forma y sentido" se conjugan en una materialidad y cómo sus efectos nos ayudan a construir sentidos.

Observaremos, a seguir, otra muestra textual que posee algunas similitudes con relación al género y el objetivo, pero se diferencia, principalmente, en cuanto al lugar discursivo y al ethos. De ese modo, la segunda viñeta que presentaremos, de autoría de Aroeira, 
se publicó en 20/11/2012, en ocasión de la visita oficial de la presidente brasileña Dilma Rousseff a España:

Muestra 2: Tira de Aroeira sobre la visita de la presidente Dilma Rousseff a España

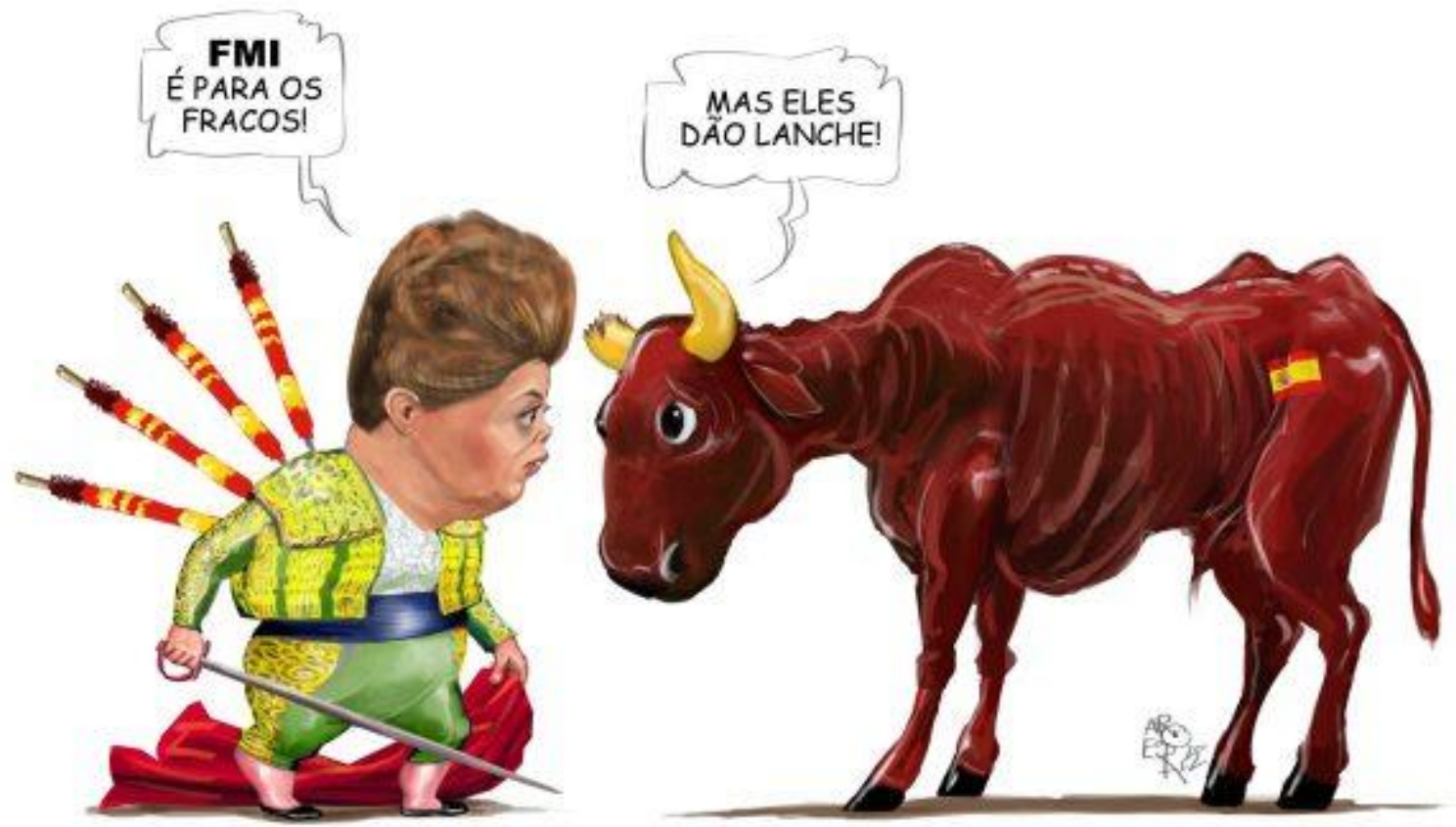

Fonte: AROEIRA, 2012.

En esta viñeta, nuevamente se presentan las referencias nacionales por medio de estereotipos ya conocidos y cristalizados en la sociedad brasileña con relación a su imaginario sobre la sociedad española: el universo simbólico de la tauromaquia. En lugar de la bandera nacional en lugar privilegiado, aquí tenemos la figura del toro y del torero con su traje de luces. Además, se presentan la bandera nacional española en la parte trasera del toro y los colores nacionales de Brasil (verde y amarillo) en la indumentaria de la figura del torero, lo que remite a los valores nacionales de ambos países. Todavía recordamos que el universo de la corrida de toros pone de manifiesto cómo el hombre comprende y articula simbólicamente el embate entre el hombre y la naturaleza, en que el hombre se presenta ante la muerte y la fuerza primitiva.

Ahora bien, este universo taurino está subvertido. La caracterización imagética del toro, animal normalmente representante de la fuerza, del coraje y de la impetuosidad en el universo simbólico español, está dibujado en la viñeta con trazos que aluden a la debilidad, a la carencia, al miedo, a la precariedad y al sufrimiento: la expresión de los ojos, el porte encorvado del cuerpo, el cuerno roto y la delgadez evidente.

Por otro lado, tenemos la figura de la presidente de Brasil en el lugar del torero, simbolizando la nación brasileña: los trazos físicos esbozados de la mandataria y el traje de luces (traje de seda ricamente adornado con hilos de oro, plata y formado de varias prendas) en los colores de la bandera brasileña (verde, amarillo y azul). Es imprescindible notar que hay un fuerte énfasis en la simbología del confronto que no solo se presenta por el antagonismo de las figuras del toro (España) versus torero (Brasil / presidente brasileña), sino por la posición 
de ataque del torero que desenvaina una espada y por la existencia de las banderillas de colores nacionales españoles (rojo y amarillo) en la espalda del torero.

Es esencial recordar que las banderillas tienen una variedad de tamaños y adornos. Hay rituales para introducirlas en el toro, pero, lo que nos interesa en este contexto es que las banderillas se las introducen en el animal en la segunda parte de la corrida de toros. En general, son aderezadas con los colores nacionales o regionales y tienen la función de adorno y de provocar el toro por medio del dolor, pero sin quitarle demasiadamente las fuerzas. Se puede intuir que la relación (de enfrentamiento) entre España y Brasil ya persiste algún tiempo, puesto que, simbólicamente, la imagen revela que ya pasamos del tercio de varas, del tercio de las banderillas y estamos, al final, en el tercio de la muerte, en que hay en enfrentamiento entre el matador y el toro.

$\mathrm{Al}$ informarse sobre los detalles de los rituales sobre las corridas de toros, podemos establecer una posible lectura considerando el momento histórico, las características del género y las condiciones de producción. De esta forma, es coherente pensar que Brasil, representado por la figura del matador, "fue atacado" anteriormente, una vez que tenemos las banderillas con los colores nacionales de España hincadas en la espalda de la personaje de la presidente brasileña. Sin embargo, en el momento de la enunciación, momento actual, Brasil tiene ventaja, ya que es el torero que tiene la espada y demuestra coraje ante el toro de imagen débil y deplorable. Más bien, la viñeta representa un determinado "momento histórico, social, económico y político" en las relaciones entre Brasil y España, pero que tiene premisas históricas sugeridas, con énfasis, por la presencia de las banderillas. Según la perspectiva esbozada por la viñeta, antes era Brasil que estaba en posición vulnerabilidad y era atacado. Sin embargo, en el momento enunciativo, ahora es España que se encuentra en este mismo lugar.

La lectura imagética de la viñeta ya indica los posibles efectos dañosos de la crisis económica española en el país, al aludir a los "sentidos" relacionados con el hambre, con la debilidad y con la humillación. Pero, la materialidad lingüística refuerza las rupturas, subversiones y discontinuidades por medio de la corruptela del proverbio "desistir é para os fracos, persistir / insistir é para os fortes", escrito en portugués. Nuevamente tenemos otro elemento cultural cargado de sentidos históricos e ideológicos.

Se desencadena el juego entre forma y sentido por medio de la sonoridad y de la rima entre el sustantivo abstracto "FMI" (Fondo Monetario Internacional), referente a la organización internacional de carácter económico y el verbo en infinitivo "desistir" que remite al proverbio. Incluso el propio proverbio podría adecuarse a este nuevo confronto: el hombre y la crisis económica, cuya metonimia podría ser la interferencia del FMI en el país, entre otras posibilidades.

La negrita que adorna la letra de la sigla enfatiza aún más los desplazamientos simbólicos de la conmutación entre "FMI" y "desistir". Además, evidencia la posición superior de Brasil con relación a España en aquel escenario económico, una vez que el enunciador articula este enunciado. Más que el ethos brasileño, la figura del torero es la figura del fiador, es decir, cuando el ethos incluye una dimensión verbal y un conjunto de características físicas y psíquicas, articulando una corporalidad, como define Maingueneau (2008). Y, en este caso, tal corporalidad se vincula a una casi caricatura de la mandataria brasileña.

El enunciado proverbial se fragmenta en dos, lo que induce a una polifonía. Y, nuevamente, presenciamos la corruptela del proverbio y la ruptura de la continuidad enunciativa, discursiva y simbólica: cuando esperamos la segunda parte del proverbio ('insistir' é para os fortes), nos encontramos, por el contrario, con el enunciado exclamativo "mas eles dão lanche!". 
Primero, la estructura rítmica se rompe por medio de un enunciado de registro informal y tono espontáneo, poco elocuente. Segundo, la estructura simbólica de la sigla FMI tiene como referente el pronombre sujeto "eles", lo que ocasiona una "concretización" de tal estructura, una vez que se explicita quienes son sus miembros, acercando los interlocutores a la realidad. La institución, antes abstracta, se convierte en algo más concreto, formado por individuos, indicados por "eles". Tercero, el sustantivo "lanche" asume un efecto de sentido determinante para el desarrollo del proyecto textual, al aludir a los sentidos de limosna, de ayuda y de precariedad. De ahí que este enunciado sea articulado por la figura del toro que asume la representación del ethos español en tal contexto de producción. Aún conviene señalar la fuerza "enunciativa" de los dos enunciados, ya que los dos tienen naturaleza exclamativa, indicada por el punto de exclamación al final de los enunciados.

Por último, el marcador discursivo "mas", del tipo conector contrargumentativo, insiere todo este fragmento del enunciado, lo que evidencia la polifonía y la articulación de voces, implícitos y sentidos. De ese modo, el conector "mas" contrapone concesivamente premisas contrarias: FMI es algo negativo (la ayuda de FMI indica debilidad y sumisión) versus FMI es algo positivo (la ayuda de FMI es necesaria, aunque sea ínfima).

Incluso, merecería la pena promover una discusión sobre el empleo de los marcadores discursivos y conectores intraoracionales, dado que muchas veces, como en el presente caso, el valor de oposición se da entre las premisas y no entre los enunciados como ya enfatizamos en Fernandes (2012). Muchas veces, las relaciones de oposición, de causa, de efecto no se dan explícitamente entre los enunciados, sino en los implícitos que provienen de su interpretación. En tal muestra, el efecto de sentido puesto en énfasis es el juicio de valor de la relación de FMI y los países en crisis, caracterizada por una vinculación desigual y de dependencia, casi de sumisión. Más bien, en el escenario simbólico y discusivo de lucha hasta la muerte, no es el hombre contra la naturaleza bruta, sino una nación ante el poder económico del FMI en un contexto de alternancia de países en situación de crisis o en situación de ascensión.

Como en el caso anterior, es posible elaborar una serie de cuestiones que desencadene algunas reflexiones, como, por ejemplo:

1) ¿Cuáles voces se articulan en la viñeta? ¿Cómo?

2) Al considerar el universo taurino, ¿cuál es la imagen estereotipada del toro y del torero y qué representan?

3) ¿Quiénes representan el toro y el torero? ¿Presentan una caracterización tradicional o hay algún tipo de ruptura? ¿Por qué?

4) ¿Cuál es el ethos y el fiador que se esbozan en la figura del matador? ¿Y en la figura del toro?

5) ¿Cuáles los efectos de sentido de los colores y sus localizaciones?

6) ¿Cuál es el efecto de sentido de la ruptura del proverbio? ¿Cuál sería el proverbio original y sus posibles contextos de uso?

7) ¿Cuáles las discursividades relacionadas con los sustantivos FMI y "lanche" en este contexto de uso?

8) ¿Cuál es el papel de FMI en el escenario económico mundial a partir de lo que se discute en la viñeta? ¿Es coherente con la realidad económica y social que vivencias?

9) ¿Cuál ethos del enunciador del texto surge de esta materialidad?

10) ¿Crees que la perspectiva presente en la viñeta es coherente con el momento histórico a que se refiere? ¿Por qué?;

11) ¿Cómo brasileño, te sientes representado por la viñeta? ¿Por qué?

Tales cuestionamientos también deben ser acompañados con un trabajo de producción oral y escrita, semejante al descrito en la viñeta anterior (producción de una viñeta y búsqueda de viñetas similares). 
Ahora bien, dada la fuerza simbólica del trasfondo taurino, sería una oportunidad ideal para discutir la simbología de la corrida de toros en España y otros países hispanohablantes o no, como Portugal y Francia, por ejemplo. Sería importante señalar algunos aspectos tales como sus orígenes antes del Medievo para representar el duelo entre el hombre y el animal o sus representaciones más mediáticas como los actuales encierros de San Fermín. Más que investigar características de esta manifestación cultural, es basilar preguntarse qué relaciones simbólicas y discursivas tal manifestación representa en cada contexto social. ¿Y en Brasil? ¿Existe alguna manifestación brasileña paralela a la española? ¿Cuáles son las representaciones y lugares simbólicos del sujeto en manifestaciones brasileñas como en la "Farra do boi" y en los "Rodeios", entre otras similares ¿Cuáles manifestaciones culturales brasileñas simbolizan el embate entre hombre y naturaleza, entre el hombre y la muerte? Para este fin, se deben buscar discursos que dialoguen con estas simbologías: el de la tradición cultural, el mercadológico, el mediático, el proteccionista, etc.

Al pensar en los textos de forma conjunta, en los dos casos, las viñetas suscitan trasfondos de representaciones estereotipadas para categorizar posiciones enunciativodiscursivas de un ethos nacional, sea por símbolos (banderas, colores), sea por referencia a manifestaciones culturales (la corrida de toros). Sin embargo, cuando utilizamos la figura del ethos como estructura que guía nuestro análisis, desarrollamos una perspectiva en que ponemos el discente en posición cuestionadora y reflexiva ante la pluralidad de sentidos en la materialidad lingüística, cultural, enunciativa y discursiva. Es más, es un reto identificar y discutir la pluralidad de discursos implícitos en la lengua e inmersos en un contexto social, histórico y político.

Nos alejamos de la peligrosa tendencia, cada vez más común entre los profesores de lengua extranjera, de que nos trasformemos en "comentadores de textos, expertos en viñetas y tiras en general". Tal actitud distancia el profesional docente de su objeto en el análisis: la materialidad lingüística que es fuente de la emergencia de sujetos, enunciados y discursos. Asimismo, trabajar con la idea de mecanismos linguísticos basados en la tradición gramática prescritita o con el parámetro de cultura como una diversidad de "espectáculos" reduccionistas en una sociedad no promueven el desarrollo de un proceso de la lectura y de la (multi)literacidad críticas, tan divulgado en los documentos oficiales al tratar del papel del lenguaje en la formación del individuo.

Los comentarios analíticos de las viñetas, cuando realizados en las clases de lengua extranjera, promueven las interrelaciones entre los interlocutores (discentes y docente) en el espacio de enseñanza, de modo que cada sujeto reflexione sobre los desplazamientos y vivencie diversos lugares enunciativo-discursivos. A partir de este punto, se pueden desarrollar varias actividades de producciones en las modalidades oral y escrita, que privilegien el papel reflexivo y activo de los alumnos y actividades con la intertextualidad que exhiban la pluralidad como un espacio de construcción de reflexiones y vivencias de ser un 'yo y un 'otro ', lo que les permitirá cuestionarse sobre los argumentos con los cuales organizan su universo simbólico de una manera y los demás de otra en el momento en que se involucran cuestiones de orden identitaria y metafísica.

En esta línea de trabajo, concordamos con la tesis de Serrani (2005, p. 15), al concebir el profesor de lenguas (materna o extranjera) como un "profesor de lengua interculturalista", capacitado para desarrollar prácticas de mediación sociocultural que enfoque conflictos identitarios y contradicciones en la materialidad lingüística. Esta noción es coherente con la idea de trabajo con la cultura en las clases de lengua extranjera, defendido por Nardi (2010, p. 401), en que: 
A cultura deva nos orientar para a consideração de seu caráter crítico e dinâmico, cultura vista, portanto, como movimento dos sujeitos em sua relação com língua e história. Por isso não basta, ao trabalhar com a cultura, "apresentar" informações a serem apreendidas e repetidas, criando a ilusão de que dominamos a cultura do outro, mas buscar compreender os processos discursivos que dão sustentação a essas manifestações sócio-culturais: analisar, portanto, não apenas as manifestações culturais como "telas" a serem descritas, mas os discursos que sobre elas (e a partir delas) se produzem.

Ao pensar a cultura como um lugar de interpretação, encontramos a possibilidade de questionar também o modo como se produzem os estereótipos, fruto talvez da ideia de que cultura é aquilo que se cristaliza. No espaço do estereótipo, olha-se para o outro como um conjunto de traços reconhecíveis que permitem ao sujeito dominá-lo e, se o desejar, ocupar o seu lugar, negando-se a complexidade e a heterogeneidade características dos sistemas culturais.

Las nociones como heterogeneidad y complejidad están en la esencia del sujeto y en su experiencia con la pluralidad. En tal contexto, seguimos las palabras de Possenti (2005, p. 166) al tratar sobre la cuestión del sujeto. Para él, lo importante no es caracterizar y nombrar el sujeto como sujetado, enunciante o psicobiológico, por ejemplo, sino observar cómo tal sujeto surge en el género A y cómo emerge de otro modo en el género B. Por lo tanto, el enfoque se centra en el proceso y no en el producto.

Así pues, trabajar con la pluralidad lingüística y cultural exige que el profesor afronte algunos desafíos. Por un lado, un conocimiento de las principales teorías relacionadas a la Gramática Descriptiva, a la Lingüística de la Enunciación, a la Lingüística Textual y a los Estudios del Discurso. Por otro, el desarrollo de una perspectiva metodológica y analítica en las clases que propicien actividades y cuestionamientos que reten los discentes y les haga reflexionar sobre sus vivencias en diversos lugares discursivos y sobre los procesos de reelaboración de la identidad y alteridad. Además, el profesor en la figura de mediador, no solo debe gestionar estas indagaciones y negociación de sentidos entre los estudiantes, sino también debe preguntarse cómo articular el entramado de voces en el propio sujeto en lengua materna y extranjera. Simbólicamente es una lucha constante "a capa y espada" por el derecho de cuestionarse y convivir con las ambivalencias y multiplicidades de y en la lengua extranjera para poder comprenderse en la lengua materna.

\section{Consideraciones finales: desarrollo de una mirada en el ejercicio crítico de la pluralidad.}

En búsqueda de una finalización, pero lejos de llegar a una perspectiva definitiva, recuperamos las reflexiones de Revuz (1997), la reafirmación de la idea de que el 'yo` de la lengua extranjera no es el de la lengua materna, lo que implica aceptar que el sujeto siempre se convierte en un otro durante el proceso de aprendizaje de una lengua. Por lo tanto, la primera obviedad (no siempre transparente) es que la pluralidad y la fragmentación ya habitan en la esencia del sujeto y este carácter está presente cuando él emerge en la materialidad lingüística. De ahí que debamos vivenciar el respeto y el cuestionamiento ante la lengua del otro que puede ser tanto la lengua extranjera como nuestra lengua materna, observada desde otro ángulo, con una mirada nueva durante nuestros desplazamientos simbólicos. Deshacerse de la ilusión de aprehender su totalidad y aceptar el reto de constantemente tener la experiencia de moverse hacia otro lugar para entender el suyo.

O que se estilhaça ao contato com a língua estrangeira é a ilusão de que existe um ponto de vista único sobre as coisas, é a ilusão de uma possível tradução termo a termo, de uma adequação da palavra à coisa. Pela intermediação da língua 
estrangeira se esboça o descolamento do real e da língua. O arbitrário do signo lingüístico torna-se uma realidade tangível, vivida pelos aprendizes na exultação... ou no desânimo (REVUZ, 1997, p. 223)

En el papel de profesor como mediador intercultural, el primer reto es que el profesional docente debe ejercitar sus capacidades analíticas, su mirada exploratoria, su habilidad de relacionar ideas, identificar (dis)junciones y afrontar los propios obstáculos para ponerse en el lugar discursivo del Otro sin dejarse llevar por simplificaciones. Es un ejercicio arduo que requiere no solo un recorrido teórico y metodológico, como también un repensar de las prácticas pedagógicas y de los modos de acercamiento e interrelaciones con los discentes y con la lengua extranjera.

En nuestro constante estado de 'impermanencia', tenemos que pensar en los procesos coenunciativos, en que constantemente estamos interpretando realidades y tejiendo, a varias manos, los sentidos. Al tener en cuenta el contexto de enseñanza del español para brasileños, recordamos el desafío célebre expuesto por Kulikowski y González (1999, p. 13) entre los profesionales del área:

[la tarea de] no reproducir y reforzar imágenes equivocadas sin crear otros problemas mayores, la de desconstruir sin destruirlo todo, la de encontrar la justa medida de esa supuesta cercanía [entre el español y el portugués].

Por esta razón, creemos que las nociones movilizadas aquí - cultura, enunciado, enunciación, ethos - son trabajadas de modo más reflexivo cuando nos guiamos por la indagación de cómo se da la emergencia del sujeto en la materialidad lingüística; cuáles procesos se dan para que forma y sentido se conjuguen y desencadenen una serie de efectos $y$, finalmente, cómo el desarrollo de una mirada atenta y crítica sobre todos estos procesos puede auxiliar un individuo a hacerse sujeto en su lengua y en su Historia, integrando, en la diversidad, otras lenguas, otras Historias y otros sujetos. Aunque compleja, quizás la idea de pluralidad y sus desafíos sea la síntesis de ese reto.

\section{REFERÊNCIAS}

AMOSSY, R. Ethos. In: CHARAUDEAU, P.; MAINGUENEAU, D. Dicionário de Análise do Discurso. 2. ed. São Paulo: Contexto, 2006.

AROEIRA. Dilma recebe pedidos da Espanha. Disponível em: < http://www.humorpolitico.com.br/governo-dilma-2/dilma-recebe-pedidos-da-espanha/ >. Postado em 2012. Acesso em: 15/06/2014.

BENVENISTE, E. Problemas de Lingüística Geral II. 2. ed. São Paulo: Pontes, 2006.

BRASIL, Ministério da Educação. Orientações curriculares para o ensino médio.

Linguagens, Códigos e suas Tecnológicas. v. 1, Brasília: Ministério da Educação, 2006.

BOSI, A. Plural mas não caótico. In: Cultura brasileira: temas e situações. 4. ed. São Paulo: Ática, 2000, p. 7-16.

CELADA, M. T. Quais as razões do espanhol como língua estrangeira para brasileiros. In: SEMINÁRIO DE LEITURA E ESCRITA EM LÍNGUA ESTRANGEIRA, 6., Anais, 
jul.2007. Disponível em: < http://alb.com.br/arquivo-

morto/edicoes_anteriores/anais16/prog_pdf/prog06_02.pdf> Acesso em: 20/04/2014.

ERLICH. Tira sobre las protestas en Brasil. Postado en 2013. Disponível em: <http://elpais.com/elpais/2013/06/18/vinetas/1371571663_039716.html>. Acesso en: 08/09/2014.

FERNANDES, I. C. S. Los marcadores discursivos a partir de una perspectiva retóricoenunciativa: cómo los efectos de sentido surgen en la lengua. In: COLOQUIO INTERNACIONAL MARCADORES DEL DISCURSO EN LENGUAS ROMÁNICAS: UN ENFOQUE CONTRASTIVO, 2., dez.2012, Actas electrónico. Disponível em: $<$ http://www.coloquiomarcadores.com.ar/archivos/Actas_II_Coloquio_internacional_marca dores.pdf $>$. Acesso em: 30/03/2014.

FIORIN, J. L. As Astúcias da Enunciação: as categorias de pessoa, espaço e tempo. 2. ed., São Paulo: Ática, 2005.

FLORES, V. N. et al. Dicionário de Linguística da Enunciação. 1. ed. São Paulo: Contexto, 2009.

FLORES, V. N.; TEIXEIRA, M. Introdução à Lingüística da Enunciação. 1. ed. São Paulo: Contexto, 2005.

GINZBURG, C. Mitos, emblemas, sinais: morfologia e historia. São Paulo: Companhia das Letras, 1989.

HALL, S. A identidade cultural. Rio Janeiro: DP\&A, 2006.

KULIZOWSKI, M. Z. M.; GONZÁLEZ, N. T. M. "Español para brasileños. Sobre por dónde determinar la justa medida de una cercanía". IN: ANUARIO BRASILEÑO DE ESTUDIOS HISPÁNICOS, BRASÍLIA: CONSEJERÍA DE EDUCACIÓN Y CIENCIA DE LA EMBAJADA DE ESPAÑA EN BRASIL, n. 9, 1999, p. 11-19.

MAINGUENEAU, D. “A propósito do Ethos”. In: MOTA, A R.; SALGADO, L. (Orgs.). Ethos discursivo. São Paulo: Contexto, 2008.

MARI, H. Os lugares do sentido. Campinas: Mercado das Letras, 2008.

NARDI, F. S. Espaços de identificação: um olhar discursivo sobre a cultura em livros didáticos para o ensino de língua espanhola. In: CONGRESSO INTERNACIONAL DE PROFESSORES DE LÍNGUAS OFICIAIS DO MERCOSUL, 1. Anais..., Foz do Iguaçu, 2010. p. 395-403. Disponível em: <

http://www.apeesp.com.br/web/ciplom/Arquivos/artigos/pdf/fabiele-nardi.pdf> Acesso em: 20/04/2014.

NARDI, F. S. Um olhar discursivo sobre língua, cultura e identidade: reflexões sobre o livro didático para o ensino de espanhol como língua estrangeira. 2007. Tese Doutorado, Universidade Federal do Rio Grande do Sul, Porto Alegre, 2007. 
POSSENTI, S. "Sírio Possenti”. In: XAVIER, A. C.; CORTEZ, S. (Orgs.). Conversas com lingüísticas: virtudes e controvérsias da Lingüística. Rio de Janeiro: Parábola, 2005.

REVUZ, C. A língua estrangeira entre o desejo de um outro lugar e o risco do exílio. In SIGNORINI, I. (Org.) Linguagem e Identidade: elementos para uma discussão no campo aplicado. São Paulo: Mercado das Letras, 1997, p.213-230.

ROMUALDO, E. C. Charge jornalística: intertextualidade e polifonia. Maringá: Eduem, 2000.

SCHÖPKE, R. Dicionário filosófico: conceitos fundamentais. São Paulo: M. Fontes, 2010.

SERRANI, S. Discurso e cultura na aula de língua. Currículo, leitura, escrita. Campinas: Pontes, 2005.

SILVA, F. L. O outro. São Paulo: M. Fontes, 2012.

WOODWARD, K. "Identidade e diferença: uma introdução teórica e conceitual”. In: SILVA, T.T.; HALL, S.; WOODWARD, K. (Orgs.). Identidade e diferença: a perspectiva dos estudos culturais. Petrópolis: Vozes, 2007, p. 07-72.

Recebido em 09/04/2014

Aprovado em 04/11/2014 